\title{
Burnout among Portuguese healthcare workers during the COVID-19 pandemic
}

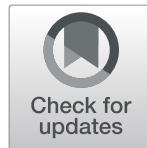

\author{
Ivone Duarte ${ }^{1,2+}$, Andreia Teixeira ${ }^{1,2 \dagger}$, Luísa Castro ${ }^{1,2,3}$, Sílvia Marina ${ }^{1,2}$, Carla Ribeiro ${ }^{4}$, Cristina Jácome ${ }^{1,2}$, \\ Vera Martins', Inês Ribeiro-Vaz ${ }^{1,2,5}$, Hugo Celso Pinheiro ${ }^{6}$, Andreia Rodrigues Silva ${ }^{7}$, Miguel Ricou ${ }^{1,2}$, Bruno Sousa ${ }^{8}$, \\ Cristiana Alves', Andreia Oliveira', Paula Silva ${ }^{9}$, Rui Nunes ${ }^{1}$ and Carla Serrão ${ }^{10^{*}}$ (D)
}

\begin{abstract}
Background: During COVID-19 pandemic, healthcare workers (HCWs) have had high workload and have been exposed to multiple psychosocial stressors. The aim of this study was to evaluate HCWs in terms of the relative contributions of socio-demographic and mental health variables on three burnout dimensions: personal, workrelated, and client-related burnout.

Methods: A cross-sectional study was performed using an online questionnaire spread via social networks. A snowball technique supported by health care institutions and professional organizations was applied.

Results: A total of 2008 subjects completed the survey. Gender, parental status, marriage status, and salary reduction were found to be significant factors for personal burnout. Health problems and direct contact with infected people were significantly associated with more susceptibility to high personal and work-related burnout. Frontline working positions were associated with all three dimensions. Higher levels of stress and depression in HCWs were significantly associated with increased levels of all burnout dimensions. Higher levels of satisfaction with life and resilience were significantly associated with lower levels of all burnout dimensions.
\end{abstract}

Conclusions: All three burnout dimensions were associated with a specific set of covariates. Consideration of these three dimensions is important when designing future burnout prevention programs for HCWs.

Keywords: COVID-19, Healthcare workers, Burnout; Stress, Depression, Resilience, Life satisfaction

\section{Background}

The impact of the COVID-19 pandemic on healthcare workers (HCWs) has been tremendous. The impact is not only related to increased workload, but also fear of the disease being contracted by themselves and their families, working with new and frequently changing protocols, limited personal protective equipment, caring for patients who are very sick and quickly deteriorating, and caring for colleagues who have also fallen ill [1-4]. This

\footnotetext{
* Correspondence: carlaserrao@ese.ipp.pt

${ }^{\dagger}$ Ivone Duarte and Andreia Teixeira contributed equally to this work.

${ }^{10}$ School of Education of Polytechnic of Porto, Centre for Research and Innovation in Education (inED), Porto, Portugal

Full list of author information is available at the end of the article
}

pandemic has exacerbated stressors in healthcare systems, in which HCWs burnout in response to workplace stress is already an epidemic [5].

According to recent studies, some HCWs have developed psychological distress [6, 7], fatigue and burnout [8], while facing the COVID-19 pandemic. The knowledge on the impact of COVID-19 on HCWs' mental health is still incipient. However, some insights on possible mental health consequences of severe infection outbreaks may be obtained from studies conducted in the settings of other outbreaks, such as Severe Acute Respiratory Syndrome (SARS) in 2003 and Middle East Respiratory Syndrome (MERS) in 2012. These studies indicate that physicians have experienced adverse

(C) The Author(s). 2020 Open Access This article is licensed under a Creative Commons Attribution 4.0 International License, which permits use, sharing, adaptation, distribution and reproduction in any medium or format, as long as you give appropriate credit to the original author(s) and the source, provide a link to the Creative Commons licence, and indicate if changes were made. The images or other third party material in this article are included in the article's Creative Commons licence, unless indicated otherwise in a credit line to the material. If material is not included in the article's Creative Commons licence and your intended use is not permitted by statutory regulation or exceeds the permitted use, you will need to obtain permission directly from the copyright holder. To view a copy of this licence, visit http://creativecommons.org/licenses/by/4.0/ The Creative Commons Public Domain Dedication waiver (http://creativecommons.org/publicdomain/zero/1.0/) applies to the data made available in this article, unless otherwise stated in a credit line to the data. 
psychological disorders such as anxiety, fear, and stigmatization during and after past outbreaks [9-11].

HCWs not only have a high exposure risk to infection, but also a high burden of mental health stress, especially those working directly with people who have or are suspected of having COVID-19 [12]. Lai et al. [6] conducted a study in China with 1257 HCWs (60.8\% nurses and $39.2 \%$ physicians), of which $41.5 \%$ were frontline professionals. They concluded that $71.5 \%$ suffered from distress, $50.4 \%$ suffered from symptoms of depression, and $44.6 \%$ suffered from anxiety, and these consequences were more evident in female nurses. Another study from China with 134 frontline workers (41\% nurses, $35.1 \%$ physicians, $23.9 \%$ support staff) showed that more than half of the HCWs had moderate to severe levels of stress perception.

Depressive and anxiety symptoms are more common among women [13]. In Italy, Rossi et al. [14] concluded that $24.7 \%$ of HCWs had symptoms of depression, $21.9 \%$ had high perceived stress, and $19.8 \%$ had anxiety symptoms. Another study conducted in Italy shows that anxiety was reported by $16,16 \%$ and depression by $20,3 \%$ of HCWs [15]. These studies help to understand the psychosocial impact of COVID-19 on HCWs, but to our knowledge, none of them explored the exposure to other recurrent stress factors that can lead to burnout [16].

A possible definition to burnout is a "state of physical, emotional and mental exhaustion that results from longterm involvement in work situations that are emotionally demanding" [17]. Burnout is experienced by the person with high level of physical, emotional and psychological fatigue [18]. In support of an integrative view of health, Kristensen et al. [17] indicate that the core of burnout is fatigue and exhaustion, defined by the dimensions of person burnout, work-related burnout and client-related burnout. Burnout has been considered a very relevant occupational health hazard among HCWs. Individuals with burnout demonstrate a reduction in professional performance, greater probability of medical error, higher rates of absenteeism, lower commitment to the job and the employer, lower job satisfaction, higher occurrence of medical leave, and greater personal suffering [19]. Also burnout can give greater probability of biological occupational injury [20,21].

$\mathrm{Hu}$ et al. [22] examined a sample of 2014 frontline nurses working in two Wuhan hospitals, and more than half of the subjects reported moderate to high burnout. Weilenmann et al. [23] investigated the level of burnout in HCWs (857 physicians and 553 nurses) in Switzerland. The results showed high levels of anxiety, depression, and burnout symptoms. With small effects, women, nurses and other HCWs who had direct interaction with COVID-19 patients reported more symptoms than colleagues who did not.
Regardless of the effects of COVID-19, several studies have already indicated the effect of many psychological variables, such as depression, stress, anxiety, resilience, and satisfaction with life in burnout syndrome [24-30]. Thus, this issue deserves particular interest in the context of a pandemic. These studies took place at different points on the pandemic curve; however, no study has assessed the burnout and mental health status immediately after the suspension of the state of emergency. The "back-to-normal scenario" must be established under strict safety measures but give people the hope to rebuild and to return to life as close to normal as possible. The protection of HCWs should be a priority and policymakers should make evidence-based decisions [31, 32].

\section{Methods}

Aim

The aim of this study was to evaluate the relative contribution of socio-demographic and mental health variables on the three burnout dimensions of HCWs facing the COVID-19 pandemic.

\section{Study design}

This cross-sectional quantitative web-based study examined HCWs living in Portugal. A survey was spread via social networks using a snowball technique and supported by health care institutions and professional organizations.

\section{Participants}

The study population comprised HCWs in the Portuguese health system, including physicians, nurses, pharmacists, nutritionists, psychologists, other allied health professionals, and healthcare assistants. Of the 2008 responding participants, 1678 (83.6\%) were women. The mean age of participants was 38 years old $(\mathrm{SD}=10)$. Of the 945 (48.6\%) participants who had children, 64\% had children who were 12 years old or younger.

The residences of the participants were divided into seven regions based on the Portuguese Territorial Units for Statistics Level II (NUTS II): North (912 participants; 45.4\%), Center (320 participants; 15.9\%), Lisbon (418 participants; 20.8\%), Alentejo (104 participants; 5.2\%), Algarve (74 participants; 3.7\%), Autonomous Region of Azores (56 participants; 2.8\%), and Autonomous Region of Madeira (124 participants; 6.2\%). Frontline HCWs were defined as those who indicating they worked faceto-face full time and part time.

\section{Procedures}

Data collection took place from May 9th to June 8th, 2020. This period included a declaration of national calamity and easing of lockdown measures that followed a 
state of national emergency (between March 18th and May 2nd). A questionnaire built in Google ${ }^{\bullet}$ Forms platform was made available to participants via a link that was shared through direct e-mail and social networks.

Ethical procedures according to the Declaration of Helsinki were accomplished via analysis and approval of the study by the Ethics Committee of São João Hospital Center (Ref 184/2020 on May 7th, 2020). All participants gave informed consent online in compliance with General Data Protection Regulation guidelines for clinical research [33].

\section{Measures and covariates}

Sociodemographic and other COVID-19-related background data were collected using a self-administered questionnaire. Psychological variables were collected using the Copenhagen Burnout Inventory (CBI); the Resilience Scale; the Depression, Anxiety, and Stress Scales (DASS-21); and the Satisfaction with Life Scale (SWLS). Burnout was measured by the validated Portuguese version of the CBI [18]. The CBI is a 19-item tool with three subscales: personal, work-related, and clientrelated burnout. The personal burnout subscale measures feelings of physical, emotional, and mental fatigue and exhaustion. The work-related burnout subscale assesses the symptoms that respondents' attribute to work. The client-related burnout subscale describes feelings of physical and psychological fatigue and exhaustion that respondents attribute to their work with patients. All items are scored on a 5-point Likert scale. The score for each subscale is the average of item scores within the subscale and ranges from 0 to 100 . Scores $\geq 50$ in each of the three subscales were considered high-level burnout $[18,34]$. These subscales are characterized by high internal consistency (original version: $\alpha=0.84$ and Portuguese version: $\alpha=0.86$, where $\alpha$ is the Cronbach's alpha) $[18,34]$. In the current study, $\alpha$ were $0.91,0.89$, and 0.89 for personal burnout, work-related burnout and clientrelated burnout, respectively.

The Resilience Scale [35] includes 25 items answered on a 7-point Likert scale ranging from strongly disagree (one) to strongly agree (seven). The Portuguese version presented high internal consistency, $\alpha=0.89$ [36]. In the current study, $\alpha=0.95$.

DASS-21 [37, 38] was used to evaluate mental health symptoms. This version consists of a 21-item 4-point Likert questionnaire that includes three self-reported subscales designed to measure the negative emotional states of depression, anxiety, and stress. Each of the three subscales contains seven items using a scale of zero (did not apply to me at all) to three (applied to me very much or most of the time). In the current study, $\alpha$ were $0.90,0.84$, and 0.90 for the depression, anxiety, and stress subscales, respectively.
SWLS is a 5-item 5-point Likert scale that assesses an individual's global judgment regarding life satisfaction $[39,40]$. The versions of this scale have acceptable or high internal consistency, original version: $\alpha=0.87$; Portuguese version: $\alpha=0.77$ [33, 34]. In this study, $\alpha=0.86$. In the Portuguese version, the scale has no cut-off point and has a possible range of 5 to 25 points.

\section{Data analysis}

Data from Google ${ }^{\circ}$ Forms were exported in a Microsoft Excel $^{-} 2016$ spreadsheet, USA, and all statistical analyses were carried out using SPSS $^{\circ}$ Statistics (version 26.0; SPSS Inc., Chicago, Illinois, USA) and Jamovi 1.1.9.0. Absolute and relative frequencies, $\mathrm{n}$ (\%) were used to describe categorical variables. Normally distributed quantitative variables were described by means and standard deviations (SDs). Nonnormally distributed quantitative variables were described by medians (Med) and interquartile intervals $\left[\mathrm{Q}_{1} ; \mathrm{Q}_{3}\right]$ (although the means and standard deviations were also presented in these cases to facilitate comparison with other studies). Normality was verified by observing the histograms.

Differences between participants were analyzed using student t-tests for normally distributed quantitative data, Mann-Whitney $U$ tests were used for quantitative nonnormally distributed data, and chi-squared tests were used for categorical data. Pearson's or Spearman's coefficient was also used to explore the association between different domains (resilience, anxiety, depression, stress, life satisfaction, and burnout). The internal consistency of each of the subscales was assessed using Cronbach's alpha $(\alpha)$, and a value above 0.7 was considered acceptable [41].

A separate multiple linear regression analysis was performed for each outcome (personal, work-related, and client-related burnout). The independent variables to include in each multiple regression were chosen by performing simple linear regressions with each variable in the dataset, including sociodemographics, variables related to COVID-19, and variables obtained from questionnaires (resilience, SWLS, and subscales from DASS-21). An additional file shows these results in more detail (see Additional file 1). All variables that correlated with the outcomes at $p \leq 0.05$ in the simple regression were included in the multiple linear regression analyses. Only the significant variables were maintained in the final multivariate models for personal, work-related, and client-related burnout.

The results of linear regressions are presented with coefficient values ( $\beta$ ), 95\% confidence intervals (95\% CIs), and $p$-values. The model was evaluated using the $\mathrm{F}$ statistic of the overall model test, $\mathrm{p}$-values, and coefficients 
of determination $\left(R^{2}\right)$. The assumptions of the linear regression models were verified as follows: a) visual analysis of histogram to assess the normality of residuals; b) a t-test to determine whether mean residuals were equal to zero; and c) plots of residuals versus the fitted predictive values to check for homoscedasticity. Values of $p \leq 0.05$ were considered significant.

\section{Results}

\section{Sample characteristics}

We received responses from 2061 respondents, but 53 respondents did not fully complete the questionnaires and were removed from the analysis. A total of 2008 HCWs completed the questionnaire.

The participants included 707 health technicians (35.2\%), 511 physicians (25.4\%), 409 nurses (20.4\%), 88 pharmacists $(4.4 \%), 83$ psychologists $(4.1 \%), 72$ nutritionists (3.6\%), 29 healthcare assistants (1.4\%) and 21 workers in allied areas (1\%). Among the participants, 157 (7.8\%) worked in high-dependency units (intensive and intermediate care), 247 (12.3\%) worked in emergency services, $485(24.2 \%)$ worked in primary healthcare, 383 (19.1\%) worked in inpatient areas and 167 (8.3\%) worked in inpatient areas exclusively for COVID19 patients.

Of all the participants, 524 (26.1\%) reported having health problems:158 (30.2\%) had a chronic respiratory disease and 119 (22.7\%) had compromised immune systems. A total of 319 (15.9\%) participants were caregivers of older people or with disabilities. The characteristics of the participants are summarized in Table 1.

\section{Results of levels of burnout dimensions and psychological variables}

The average levels of burnout among HCWs were divided into low and high burnout groups. High levels of personal burnout were found in 1055 (52.5\%) participants, and high work-related burnout was found in 1066 (53.1\%). Resilience was moderate in 1021 (50.8\%). Anxiety $(66.9 \%)$, depression (70.6\%) and stress $(63.4 \%)$ were normal in most of participants (Table 2). The HCWs also showed high satisfaction with life with a median of 18 [14; 20] points.

Results of personal burnout, work-related burnout, and client-related burnout subscales: multivariate analysis

Socio-demographic, professional and psychological variables were identified as potential predictors according to the multiple linear regression (Table 3). Sex, parental status, marriage status and salary reduction were found to be significant factors for personal burnout. Women personal burnout levels were 4.51 points higher on average in comparison with men $(p<0.001)$. Having children under 12 years was associated with higher levels of
Table 1 Sample characteristics of participants $(n=2008)$

\begin{tabular}{|c|c|c|}
\hline Characteristics & $\mathrm{n}$ & $\%$ \\
\hline \multicolumn{3}{|l|}{ Marital status } \\
\hline Single & 780 & 38.8 \\
\hline Married/nonmarital partnership & 1071 & 53.3 \\
\hline Divorced or Separated & 141 & 7.0 \\
\hline Widowed & 16 & 0.8 \\
\hline \multicolumn{3}{|l|}{ Parents } \\
\hline Yes & 975 & 48.6 \\
\hline No & 1033 & 51.4 \\
\hline \multicolumn{3}{|c|}{ Lives with a person at risk for COVID-19 infection } \\
\hline Yes & 681 & 33.9 \\
\hline No & 1327 & 66.1 \\
\hline \multicolumn{3}{|c|}{ Death of relative or friend during the pandemic period } \\
\hline Yes & 118 & 5.9 \\
\hline No & 1890 & 94.1 \\
\hline \multicolumn{3}{|l|}{ Education level } \\
\hline Graduate & 1207 & 60.1 \\
\hline Postgraduate & 801 & 39.9 \\
\hline \multicolumn{3}{|l|}{ Professional experience } \\
\hline Five years or less & 504 & 25.1 \\
\hline From 6 years to 15 years & 745 & 37.1 \\
\hline More than 15 years & 759 & 37.8 \\
\hline \multicolumn{3}{|l|}{ Frontline working position } \\
\hline Yes & 1398 & 69.7 \\
\hline No & 609 & 30.3 \\
\hline \multicolumn{3}{|l|}{ Direct contact with infected people } \\
\hline Yes & 552 & 27.5 \\
\hline No & 1456 & 72.5 \\
\hline \multicolumn{3}{|l|}{ Salary reduction } \\
\hline Yes & 710 & 35.4 \\
\hline No & 1298 & 64.6 \\
\hline \multicolumn{3}{|l|}{ Diagnosed health problem } \\
\hline Yes & 524 & 26.1 \\
\hline No & 1484 & 73.9 \\
\hline \multicolumn{3}{|l|}{ COVID-19 Tested } \\
\hline Yes and, no but l'd like to do it & 1487 & 74.1 \\
\hline No, I have no interest & 521 & 25.9 \\
\hline
\end{tabular}

personal burnout $(\beta=3.68 ; p<0.001)$. Being diagnosed with health problems was associated with higher personal burnout $(\beta=1.84 ; p<0.05)$ and work-related burnout $(\beta=1.68 ; p<0.05)$. Single status was associated with significantly less personal burnout than marriage status/ nonmarital partnerships $(\beta=-2.90, p<0.001)$. Salary reduction was significantly associated with lower personal burnout levels $(\beta=-1.94, p<0.05)$. Frontline working 
Table 2 Descriptive statistics for burnout dimensions, resilience, anxiety, depression, and stress

\begin{tabular}{|c|c|c|}
\hline Variable & $\mathbf{n}$ & $\%$ \\
\hline \multicolumn{3}{|l|}{ Personal burnout } \\
\hline Low level & 953 & 47.5 \\
\hline High level & 1055 & 52.5 \\
\hline \multicolumn{3}{|l|}{ Work-related burnout } \\
\hline Low level & 942 & 46.9 \\
\hline High level & 1066 & 53.1 \\
\hline \multicolumn{3}{|c|}{ Client-related burnout } \\
\hline Low level & 1297 & 64.6 \\
\hline High level & 711 & 35.4 \\
\hline \multicolumn{3}{|l|}{ Resilience } \\
\hline Low & 428 & 21.3 \\
\hline Moderate & 1021 & 50.8 \\
\hline High & 559 & 27.8 \\
\hline \multicolumn{3}{|l|}{ Anxiety } \\
\hline Normal & 1344 & 66.9 \\
\hline Mild & 121 & 6.0 \\
\hline Moderate & 302 & 15.0 \\
\hline Severe & 101 & 5.0 \\
\hline Extremely severe & 140 & 7.0 \\
\hline \multicolumn{3}{|l|}{ Depression } \\
\hline Normal & 1418 & 70.6 \\
\hline Mild & 209 & 10.4 \\
\hline Moderate & 228 & 11.4 \\
\hline Severe & 85 & 4.2 \\
\hline Extremely severe & 68 & 3.4 \\
\hline \multicolumn{3}{|l|}{ Stress } \\
\hline Normal & 1274 & 63.4 \\
\hline Mild & 240 & 12.0 \\
\hline Moderate & 250 & 12.5 \\
\hline Severe & 171 & 8.5 \\
\hline Extremely severe & 73 & 3.6 \\
\hline
\end{tabular}

positions were associated with higher levels of personal burnout, work-related burnout, and patient-related burnout $(\beta=4.24, \quad \beta=3.91$, and $\beta=2.35, \quad p<0.001$, respectively).

HCWs who had direct contact with COVID-19 patients presented higher personal burnout levels $(\beta=3.27$, $p<0.001)$ and work-related burnout levels $(\beta=3.45, p<$ $0.001)$. Higher levels of stress and depression in HCWs were significantly associated with higher levels of all burnout dimensions $(p<0.001)$. As presented in Table 3, higher levels of satisfaction with life and resilience were significantly associated with lower levels of all burnout dimensions.

\section{Discussion}

Portuguese HCWs followed the trend of burnout seen in studies from other countries [23, 42]. Our findings show that more than half of HCWs experienced high levels of personal and work-related burnout, while most participants $(64.6 \%)$ had low rates of client-related burnout. The results of psychological variables showed moderate resilience in $50.8 \%$ of the sample and normal levels for anxiety (66.9\%), depression (70.6\%) and stress (63.4\%) in most of the participants. Notably, $74.9 \%$ of participants had six or more years of professional experience, which could contribute to a greater ability to manage anxiety and stress. Professional experience improves one's clear awareness to solve problems, which can increase one's confidence in professional actions, thus inducing less stress and anxiety.

The COVID-19 pandemic seems to have had an impact on the physical and psychological wellbeing of HCWs worldwide [5]. It is not unexpected that this new coronavirus has posed unprecedented challenges to HCWs. Previous research on burnout has already found that the highest prevalence rate of burnout occurs among HCWs in hospital emergencies [11]. Without comparing this situation to the pandemic, we emphasize that HCWs in hospital emergencies also deal with crisis situations. Thus, in a pandemic, exacerbation of this situation would be inevitable.

Emotional exhaustion related to low levels of mental health has been reported [7, 11], and effective interventions to support health care professionals are needed. Although the demands of medical practice may be a significant contributor to burnout, personal and family stressors may impose additional pressures. The COVID-19 pandemic has disrupted healthcare systems worldwide. A prolonged response period to the pandemic will lead to additional stress for HCWs, which will permeate further throughout the healthcare system [43].

Our findings reinforce the multidimensionality of the burnout syndrome. Indeed, each of the three burnout dimensions was associated with a specific set of covariates. Thus, consideration of these three dimensions is important when designing future burnout prevention programs for HCWs.

The contributions of socio-demographic and psychological variables on the three burnout dimensions were explored. We found that sex, marriage status, parental status, frontline worker positions, and direct contact with infected people significantly contributed to the outcomes. Our findings suggest that female sex is associated with higher levels of personal burnout, which is in line with previous research $[44,45]$. These results might be explained by the double-workload role of women in society between their professions and home lives. These 
Table 3 Regression coefficients for CBI subscales as outcomes and socio-demographic, professional, and emotional variables as predictors from univariate multiple linear regressions

\begin{tabular}{|c|c|c|c|}
\hline Variables & $\begin{array}{l}\text { Personal Burnout } \\
\beta[95 \% \mathrm{Cl}]\end{array}$ & $\begin{array}{l}\text { Work-related Burnout } \\
\beta[95 \% \mathrm{Cl}]\end{array}$ & $\begin{array}{l}\text { Client-related Burnout } \\
\beta[95 \% \mathrm{Cl}]\end{array}$ \\
\hline \multicolumn{4}{|l|}{ Gender } \\
\hline Male & Reference & & \\
\hline Female & $4.51[2.71-6.31]^{* * *}$ & & \\
\hline \multicolumn{4}{|l|}{ Marital status } \\
\hline Married/nonmarital partnership & Reference & & \\
\hline Single & $-2.90[-4.52 ;-1.29]^{* * *}$ & & \\
\hline Divorced or Separated & $-2.46[-5.18 ; 0.26]$ & & \\
\hline Widowed & $-2.96[-10.44 ; 4.52]$ & & \\
\hline \multicolumn{4}{|l|}{ Parental status } \\
\hline No or older than 12 years old & Reference & & \\
\hline Yes, with 12 years old or less & $3.68[2.03 ; 5.33]^{* * *}$ & & \\
\hline \multicolumn{4}{|l|}{ Education level } \\
\hline Elementary or secondary school & & Reference & \\
\hline Graduate & & $3.91[-0.11 ; 7.93]$ & \\
\hline Postgraduate & & $6.28[0.44 ; 12.13]^{*}$ & \\
\hline Master's degree & & $5.76[1.68 ; 9.84]^{* *}$ & \\
\hline $\mathrm{PhD}$ & & $6.23[0.69 ; 11.77]^{* *}$ & \\
\hline \multicolumn{4}{|l|}{ Professional experience } \\
\hline Five years or less & & & Reference \\
\hline From 6 years to 15 years & & & $4.46[2.13 ; 6.78]^{* * *}$ \\
\hline More than 15 years & & & $-0.80[-3.12 ; 1.52]^{*}$ \\
\hline Frontline working position & $4.24[2.55 ; 5.93]^{* * *}$ & $3.91[2.41 ; 5.43]^{* * *}$ & $2.35[0.40 ; 4.31]^{*}$ \\
\hline Salary reduction & $-1.94[-3.50 ;-0.38]^{*}$ & & \\
\hline Diagnosed health problem & $1.84[0.30 ; 3.38]^{*}$ & $1.68[0.17 ; 3.19]^{*}$ & \\
\hline \multicolumn{4}{|l|}{ COVID-19 Tested } \\
\hline Yes and, no but l'd like to do it & Reference & & \\
\hline No, I have no interest & $-3.13[-4.65 ;-1.61]^{* * *}$ & & \\
\hline Direct contact with infected people & 3. $27[1.70 ; 4.83]^{* * *}$ & $3.45[1.89 ; 5.00]^{* * *}$ & \\
\hline Death of relative or friend during pandemic period & & & $-4.68[-8.49 ;-0.87]^{*}$ \\
\hline Resilience & $-0.08[-0.11 ;-0.05]^{* * *}$ & $-0.05[-0.08 ;-0.02]^{* *}$ & $-0.07[-0.12 ;-0.03]^{* *}$ \\
\hline Satisfaction with life & $-0.78[-0.98 ;-0.58]^{* * *}$ & $-1.16[-1.35 ;-0.96]^{* * *}$ & $-1.11[-1.38 ;-0.85]^{* * *}$ \\
\hline Anxiety & $0.33[0.04 ; 0.62]^{* * *}$ & & \\
\hline Depression & $0.68[0.41 ; 0.95]^{* * *}$ & $0.82[0.56 ; 1.07]^{* * *}$ & $0.69[0.34 ; 1.03]^{* * *}$ \\
\hline Stress & $1.66[1.41 ; 1.90]^{* * *}$ & $1.29[1.09 ; 1.50]^{* * *}$ & $0.79[0.51 ; 1.07]^{* * *}$ \\
\hline$R^{2}$ & 0.475 & 0.407 & 0.187 \\
\hline$F$ & $120^{* * *}$ & $125^{* * *}$ & $57.5^{* * *}$ \\
\hline
\end{tabular}

Note. $\mathrm{Cl}$ confidence interval. ${ }^{*} p \leq 0.05 ;{ }^{* *} p \leq 0.01 ;{ }^{* * *} p \leq 0.001$

multiple responsibilities could result in a greater perception of personal burnout.

People who were single, widowed or divorced seemed to be were less susceptible to personal burnout than those who were married. This finding could be related to the dual role that married HCWs play, especially women, who were most of participants (83.6\%) in this study. Such an association has been reported previously in a study on nurses [46].

HCWs with children under 12 years old were more likely to experience personal burnout than HCWs without children or children older than 12 years (during the 
period of data collection, the state allowed parents who had children up to the age of 12 years to work from home [47]. This was an interesting finding of the study since the roles of HCWs as parents and primary caregivers at home have rarely been investigated. With the spread of the coronavirus and the suspension of classes in schools, teleworking was encouraged. Parents have to juggle their roles as parents, workers, and many times, as teachers to help their children. Teleworking during the COVID-19 pandemic requires separating work and personal time, which could cause family obligations to intrude on work and work obligations to bleed into family time. This might lead teleworkers to work extra hours, resulting in burnout.

Working on the "frontline" is one of the few covariables that was significantly associated with all three dimensions of burnout. In a study conducted in China, the prevalence of burnout was high among frontline nurses [22]. The COVID-19 outbreak has led to a sharp increase in admissions and presentations to hospitals, which has impacted the workload of HCWs. Prior to this pandemic situation, these professionals were already considered as one of the groups most exposed to psychosomal risks [11]. The pandemic has exacerbated existing risks and triggered new risks, including risk of exposure to the pathogen, long working hours, increased volume and severity of patients, critical decision making, psychological distress, fatigue and the high concern that professionals could be potential vectors of disease transmission to their families.

Exposure to these risk factors can jeopardize the mental, physical, emotional, and social wellbeing of these professionals as well as the care process. It can also make it difficult for professionals to establish adequate therapeutic relationships. In the same direction, the significant determinants of personal and work-related burnout were health problems and directly participation in the diagnosis, treatment, and care for COVID-19 patients. A study carried out in Switzerland with HCWs demonstrated higher levels of burnout in the group that was in direct contact with patients [23].

Resilience, satisfaction with life, depression and stress were found to be potential predictors for all burnout dimensions, and anxiety was a potential predictor for personal burnout. The relationship between burnout and psychological dimensions has been documented in recent studies [26]. In this context, it can be argued that life satisfaction is a protector against developing burnout [30]. In this study, satisfaction with life seems to be a protective factor for burnout, which confirms previous research in this field.

A significant relationship was found between depression and all the dimensions of burnout, which highlights the importance of the problem and its prevention. Our findings are in line with the results from other studies $[25,26]$. Several studies [24, 25] found consistent medium to high correlations between depression and burnout. According to our results, depression was identified as a potential predictor of burnout. Depression can have a negative impact on the health, performance, and productivity of workers, which can influence the quality of care provided and patients' health [28]. To prevent negative impacts, coping strategies and resilience could have important roles [28]. In fact, according to our results, resilience was found to be a potential protective factor against burnout. In previous research, resilience was also found to be a protective factor for regulating and preventing burnout [27]. Resilience can be a psychological resource in performing emotional labor, and resilience-promotion programs should be implemented.

Stress also seems to be a risk factor for burnout. High levels of stress have serious consequences for the wellbeing of individuals and can lead to mental fatigue, difficulty in concentration, loss of immediate memory, and anxiety [48]. On the other hand, it could also empower an individual to deal with changing and adverse situations. Stress and burnout seem to be inseparable [29]. In a randomized controlled trial, Stier-Jarmer et al. [29] found that a program for stress reduction and burnout prevention was effective. The program aimed at reducing currently perceived stress, as well as providing strategies for dealing with stressors. The optimization of stressmanagement skills should be required.

Anxiety can be considered a reaction to threatening situations that acts as a protective factor [49]. However, if the anxiety is prolonged over the time it can result in suffering with an impact on the individual's functioning [49]. According Spielberger [50], anxiety is divided in two types, trait anxiety and state anxiety. Trait anxiety is the individual proneness to anxiety, that is, the level how the person perceives stressful situations as threatening, and state anxiety is the reaction toward a situation after having judged it as threatening [50]. Anxiety seems to be a potential risk factor for personal burnout but not for work and client-related burnout. Personal burnout subscale measures physical and psychological fatigue, work-related burnout assesses the level of exhaustion and fatigue that derive from work, and client-related burnout analyze exhaustion because of the relation with clients [18]. Our findings suggest that exhaustion and fatigue does not derive from work or relation with the clients, but a consequence from physical and psychological fatigue. As stated, $69.7 \%$ of the study participants were frontline workers which required more personal effort and may have contributed to greater physical and psychological exhaustion. In addition, in the frontline, workers are faced with stressful situations and the level how the person perceives these situations as threatening 
can be higher. The literature in this field, in addition to advancing the existence of a correlation between anxiety and burnout, argues that this relationship is still unclear and further research is needed [26].

\section{Limitations}

This study offered several interesting discoveries. However, some limitations should be considered. This study used a cross-sectional online survey, which might have limited the accessibility of people less familiar with the internet or less prone to using it. The sample was obtained by a snowball technique and might have not reached some classes or individuals. The study was carried out during a one-month period and is related to only a specific pandemic period, which corresponded to a relief of lockdown measures. In addition, has a transversal character and no data was analyzed before pandemic. No retrospective information was collected. Further investigation could ask if participants suffered of those symptoms before Covid-19 pandemic and if the symptoms increased during the pandemic.

Also, there could be a bias linked to socially desirable responding, that is, the tendency to reply to a questionnaire while giving a favorable image of oneself or to comply with the investigation goal. Future research could use the Social Desirability Scale, in association with the other tools used in this investigation, to improve the validity of questionnaire-based research.

\section{Conclusions}

HCWs experience high burnout, which warrants attention and support from policy makers. Factors that potentially contribute to the level of burnout of HCWs include sex, marriage status, having children 12 years old or younger, education level, years of professional experience, frontline work, health problems and direct contact with infected people. It is essential to pay attention to the psychological wellbeing of these professionals. Occupational health surveillance can play an important role to improve HCWs wellbeing [51].

Measures could include the implementation of a recovery plan for these HCWs and the development of strategies for resilience training and self-care. Such efforts could increase the protective factors against environmental risks like those in the current pandemic, as well as develop positive factors for mental health. Also, is important, asking for help from other professionals ensures different perspectives. The more experience a professional has the greater is the probability he or she will simplify information. Intervention groups and supervision to discuss their interpretations and proposals for intervention with colleagues can be important and may act as a protective measure in several ways, both in professional practice and in promoting psychological well-being.

\section{Supplementary Information}

The online version contains supplementary material available at https://doi. org/10.1186/s12889-020-09980-z.

Additional file 1:. Factors associated with personal, work, and clientrelated burnout identified by simple linear regression. The independent variables to include in each multiple regression were chosen by performing simple linear regressions with each variable in the dataset.

\section{Abbreviations}

HCWs: Healthcare workers; SARS: Severe Acute Respiratory Syndrome; MERS: Middle East Respiratory Syndrome; SD: Standard deviation; NUTS II: Portuguese Territorial Units for Statistical Level II; Ref: Reference; CBI: Copenhagen Burnout Inventory; DASS-21: Depression, Anxiety, and Stress Scales; SWLS: Satisfaction with Life Scale; a: Cronbach's alfa; USA: United States of America; SPSS: Statistical Package for the Social Sciences; n: Absolute frequencies; SD: Standard deviation; Med: Medians; Q1: First quartile; Q3: Third quartile; P: $p$-value; $\beta$ : Coefficient value; Cls: Confidence intervals; $R^{2}$ : Coefficient of determination

\section{Acknowledgements}

We would like to thank the following institutions and professional organizations for promoting the study on their internet platforms: Faculty of Medicine of University of Porto, School of Education of Polytechnic of Porto, Centre for Research and Innovation in Education (inED) and the Center for Health Technology and Services Research (CINTESIS). We wish to acknowledge the National Union of Senior Health Technicians in the Diagnostic and Therapeutic Areas, Portuguese Nurses Association, Portuguese Association of Physiotherapists, Order of Nutritionists, Order of Portuguese Nurses, Portuguese Nutrition Association, Nutritionists Portugal, Portuquese Nurses Union, Independent Doctors Union, and Order of Portuguese Psychologists and the Regional Pharmacovigilance Units (Porto, Guimarães, Lisboa, Santarém e Setúbal, Beira Interior, Coimbra e Algarve e Baixo Alentejo) for informing their associates about the study. Additional Contributions: We thank all the HCWs who participated in this study.

\section{Authors' contributions}

ID contributed to the design, data collection, analysis and interpretation of data and drafting the article. AT contributed to the design, data collection, analysis and interpretation of data and drafting the article. LC contributed to data collection, analysis and interpretation of data. SM contributed to the interpretation of the data and revised critically the article. CR, CJ, VM, IRV, HCP, ARS, MR, BS, CA, AO, PS and RN contributed to the data collection and revised critically the article. CS contributed to the design, data collection, analysis and interpretation of data, drafting the article and revised critically the article. All authors read and approved the final manuscript.

\section{Funding}

This work was supported by the National Funds through FCT - Fundação para a Ciência e a Tecnologia, I.P., within CINTESIS, R\&D Unit (reference UIDB/ 4255/2020). The funding bodies had no role in the design of the study, collection, analysis, and interpretation of data or in writing the manuscript.

\section{Availability of data and materials}

The datasets during or analyzed during the current study are available from the corresponding author on reasonable request.

\section{Ethics approval and consent to participate}

Ethical procedures were accomplished via analysis and approval of the study by an independent Ethical Committee (Comissão de Ética para a Saúde -

Centro Hospitalar de São João [Ethics Committee of São João Hospital Center]) with the code number 184/2020. All health care professionals participated in the study anonymously. Informed consent was obtained from all participants included in the study by written selecting a tick box indicating they understood the terms of the study and consented. 


\section{Consent for publication}

Not applicable.

\section{Competing interests}

The author(s) declared no potential competing interests with respect to the research, authorship, and/or publication of this article.

\section{Author details}

${ }^{1}$ MEDCIDS - Department of Community Medicine, Information and Health Decision Sciences, University of Porto, Porto, Portugal. ${ }^{2}$ CINTESIS - Center for Health Technology and Services Research, Faculty of Medicine, University of Porto, Porto, Portugal. ${ }^{3}$ School of Health of Polytechnic of Porto, Porto, Portugal. ${ }^{4}$ Pulmonology Department, Centro Hospitalar de Vila Nova de Gaia/ Espinho, Vila Nova de Gaia, Portugal. ${ }^{5}$ Porto Pharmacovigilance Centre, Faculty of Medicine, University of Porto, Porto, Portugal. ${ }^{6}$ Department of Internal Medicine, Tâmega e Sousa Hospital Center, Penafiel, Porto, Portugal. ${ }^{7}$ Darque Health Care Center, Alto Minho Local Healtn Care Center, Viana do Castelo, Portugal. ${ }^{8} \mathrm{CBIOS}$ - Research Center for Biosciences and Health Technologies, Lisboa, Portugal and Health Service of Autonomous Region of Madeira, Funchal, Portugal. ${ }^{9}$ Portuguese Institute of Oncology of Porto, Porto, Portugal. ${ }^{10} \mathrm{School}$ of Education of Polytechnic of Porto, Centre for Research and Innovation in Education (inED), Porto, Portugal.

\section{Received: 25 September 2020 Accepted: 26 November 2020}

Published online: 07 December 2020

\section{References}

1. Albott CS, Wozniak JR, McGlinch B, Wall MH, Gold BS, Vinogradov S. Battle buddies: rapid deployment of a psychological resilience intervention for health care workers during the COVID-19 pandemic. Anesth Analg. 2020; 131(1):43-54.

2. Senni M. COVID-19 experience in Bergamo, Italy. Eur Heart J. 2020;41:178397. https://doi.org/10.1093/eurheartj/ehaa279.

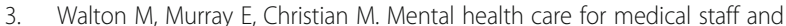
affiliated healthcare workers during the COVID-19 pandemic. Eur Heart J Acute Cardiovasc Care. 2020;9(3):241-7.

4. Chirico F, Nucera G, Magnavita N. Protecting the mental health of healthcare workers during the COVID-19 emergency. BJ Psych Int. 2020:1-6.

5. Restauri N, Sheridan AD. Burnout and posttraumatic stress disorder in the coronavirus disease 2019 (COVID-19) pandemic: intersection, impact and interventions. J Am Coll Radiol. 2020;17(7):921-6.

6. Lai J, Ma S, Wang Y, Cai Z, Hu J, Wei N, Wu J, Du H, Chen T, Li R, et al. Factors associated with mental health outcomes among health care workers exposed to coronavirus disease 2019. JAMA Netw Open. 2020;3(3): $1-12$.

7. Zhang S, Wang J, Xie F, Yin D, Shi Y, Zhang M, Yin H, Li F, Yang L, Cao D, Sun T. A cross-sectional study of job burnout, psychological attachment, and the career calling of Chinese doctors. BMC Health Serv Res. 2020; 20(193):2-11.

8. World Health Organization. Mental health and psychosocial considerations during the COVID-19 outbreak: 18 March 2020 (No. WHO/2019-nCoV/ MentalHealth/2020.1). 2020. https://www.who.int/docs/default-source/ coronaviruse/mental-health-considerations.pdf. Accessed 12 Jul 2020.

9. Li L, Wan C, Ding R, Liu Y, Chen J, Wu Z, Liang C, He Z, Li C. Mental distress among Liberian medical staff working at the China Ebola treatment unit: a cross sectional study. Health Qual Life Outcomes. 2015;13:156.

10. McAlonan GM, Lee A, Cheung V, Cheung C, Tsang K, Sham P, Chua S, Wong J. Immediate and sustained psychological impact of an emerging infectious disease outbreakon health careworkers. Can J Psychiatr. 2007;52(4):241-7.

11. Portero S, Cebrino J, Herruzo J, Vaquero M. Factors related to the probability of suffering mental health problems in emergency care professionals. Rev Lat Am Enferm. 2019;27(e3144):3079-144. https://doi.org/10.1590/1518-8345. 3079-3144.

12. Xiang YT, Yang Y, Li W, Zhang L, Zhang Q, Cheung T, Chee H. Timely mental health care for the 2019 novel coronavirus outbreak is urgently needed. Lancet Psychiatry. 2020;7:228-9.

13. Du J, Dong L, Wang T, Yuan C, Fu R, Zhang L, Liu B, Zhang M, Yin Y, Qin J, et al. Psychological symptoms among frontline healthcare workers during COVID-19 outbreak in Wuhan. Gen Hosp Psychiatry. 2020;S0163-8343(20): 30045-1. https://doi.org/10.1016/j.genhosppsych.2020.03.011..
14. Rossi R, Socci V, Talevi D, Mensi S, Niolu C, Paciti F, Di Marco A, Rossi A, Siracusano A, Di Lorenzo G. COVID-19 pandemic and lockdown measures impact on mental 1 health among the general population in Italy. 2020. doi: https://doi.org/10.1101/2020.04.09.20057802. Accessed 12 Jul 2020.

15. Magnavita N, Tripepi G, Di Prinzio RR. Symptoms in health care workers during the COVID-19 epidemic. A cross-sectional survey. Int J Environ Res Public Health. 2020 Jul 20;17(14):5218.

16. Sinval J, Queirós C, Pasian S, Marôco J. Transcultural adaptation of the Oldenburg burnout inventory (OLBI) for Brazil and Portugal. Front Psychol. 2019:19(338):1-28.

17. Schaufeli WB, Greenglass ER. Introduction to special issue on burnout and health. Psychol Health. 2001;16:501-10.

18. Kristensen TS, Borritz M, Villadsen E, Christensen KB. The Copenhagen burnout inventory: a new tool for the assessment of burnout. Work Stress. 2005;19(3):192-207.

19. Marôco J, Marôco AL, Leite E, Bastos C, Vazão MJ, Campos J. Burnout em profissionais da saúde Portugueses: Uma análise a nível nacional. Acta Medica Port. 2016;29(1):24-30.

20. Chirico F, Magnavita N. Covid-19 infection in Italy: An occupational injury. S Afr Med J. Published online 8 May 2020. https://doi.org/10.7196/SAMJ.2020. v110i6.14855.

21. Chirico F, Nucera G. Tribute to healthcare operators threatened by COVID19 pandemic. J Health Soc Sci. 2020;5(2):165-8. https://doi.org/10.19204/ 2020/trbt1.

22. Hu D, Kong Y, Li W, Han Q, Zhang X, Zhu LX, Wan SW, Liu Z, Shen Qu, Yang $J$ et al. Frontline nurses' burnout, anxiety, depression, and fear statuses and their associated factors during the COVID-19 outbreak in Wuhan, China: A Big-Scale Cross-Sectional Study. 2020. doi: https://doi.org/10.2139/ssrn. 3566144. Accessed 12 Jul 2020.

23. Weilenmann S, Ernst J, Petry H, Pfaltz MC, Sazpinar O, Gehrke S, Francesca P, Känel R, Spiller TR. Health care Worker's mental health during the first weeks of the Sars-CoV-2 pandemic in Switzerland: a cross-sectional study. 2020. https://www.ncbi.nlm.nih.gov/pmc/articles/PMC7084952/pdf/ijerph-17-0172 9.pdf. Accessed 12 Jul 2020.

24. Ahola K, Hakanen J, Perhoniemi R, Mutanen P. Relationship between burnout and depressive symptoms: a study using the person centred approach. Burn Res. 2014;1:29-37.

25. Bianchi R, Boffy C, Hingray C, Truchot D, Laurent E. Comparative symptomatology of burnout and depression. J Health Psychol. 2013;18(6): 782-7.

26. Koutsimani P, Montgomery A, Georganta K. The relationship between burnout, depression, and anxiety: a systematic review and meta-analysis. Front Psychol. 2019;10:284-98.

27. Lee Y, Lee J, Kim J, Shin I, Yoon J, Kim S. A comparative study of burnout, stress, and resilience among emotional workers. Psychiat Invest. 2019;16(9): 686-94.

28. Ramirez-Baena L, Ortega-Campos E, Gomez-Urquiza J, Fuente G, FuenteSolana E, Fuente G. A multicentre study of burnout prevalence and related psychological variables in medical area hospital nurses. J Clin Med. 2019; 8(1):92.

29. Stier-Jarmer M, Frisch D, Oberhauser C, Berberich G, Schuh A. The effectiveness of a stress reduction and burnout prevention program: a randomized controlled trial of an outpatient intervention in a health resort setting. Dtsch Arztebl Int. 2016;113:781-8. https://doi.org/10.3238/arztebl. 2016.0781.

30. Uchmanowicz I, Manulik S, Lomper K, Rozensztrauch A, Rosińczuk J. Life satisfaction, job satisfaction, life orientation and occupational burnout among nurses and midwives in medical institutions in Poland: A crosssectional study. BMJ Open. 2019;9:e024296.

31. Chirico F, Nucera G, Magnavita N. COVID-19: protecting healthcare workers is a priority [published online ahead of print, 2020 Apr 17]. Infect Control Hosp Epidemiol. 2020;41(9):1117. https://doi.org/10.1017/ice.2020.148 Epub 2020 Apr 17.

32. Chirico F, Magnavita N. Burnout Syndrome and Meta-Analyses: Need for Evidence-Based Research in Occupational Health. Comments on Prevalence of Burnout in Medical and Surgical Residents: A Meta-Analysis. Int. J. Environ. Res. Public. Health. 2019, 16, doi:https://doi.org/10.3390/ ijerph16091479. Int J environ res public health. 2020;17(3):741. Published 2020 Jan 23.

33. Marina S, Duarte I, Ricou M. Informed consent in clinical research in Portugal: promotion of good practices. Acta Méd Port. 2020;33(7-8):453-5. 
34. Fonte CMS. Adaptação e validação Para português do questionário de Copenhagen burnout inventory [adaptation and validation of the Copenhagen burnout inventory questionnaire]. Master thesis. Coimbra: Faculdade de Economia da Universidade de Coimbra; 2011.

35. Wagnild GM, Young H. Development and psychometric evaluation of the resilience scale. J Nurs Meas. 1993;1(2):165-78 PMID: 7850498.

36. Oliveira MF, Machado TS. Tradução e validação da escala de resiliência Para estudantes do ensino superior [translation and validation of the resilience scale for higher education students]. Anál Psicológica. 2011;29(4):579-91 https://psycnet.apa.org/record/2012-02842-007.

37. Lovibond $\mathrm{P}$, Lovibond $\mathrm{S}$. The structure of negative emotional states: comparison of the depression anxiety stress scales (DASS) with the Beck depression and anxiety inventories. Behav Res Ther. 1995;33(3):335-43.

38. Pais-Ribeiro JL, Honrado A, Leal I. Contribuição Para o estudo da adaptação Portuguesa das escalas de ansiedade, depressão e stress (EADS) de 21 itens de Lovibond e Lovibond [contribution to the study of the Portuguese adaptation of anxiety, depression and stress scales (EADS) of 21 items by Lovibond and Lovibond]. Psic, Saúde Doenças. 2004;5(2):229-39 http:// www.scielo.mec.pt/pdf/psd/v5n2/v5n2a07.pdf.

39. Diener ED, Emmons RA, Larsen RJ, Griffin S. The satisfaction with life scale. J Pers Assess. 1985;49:71-5.

40. Simões A. Ulterior validação de uma escala de satisfação com a vida (SWLS) [Validation of a life satisfaction scale]. Rev PortuguesaPedagogia. 1992;26(3): 503-15.

41. Kline RB. Principles and practice of structural equation modeling. 3rd ed. New York: Guilford Press; 2010

42. Morgantini L, Naha U, Wang H, Francavilla S, Acar Ö, Flores J, Crivellaro S, Moreira $D$, Abern $M$, Eklund $M$ et al. Factors contributing to healthcare professional burnout during the COVID-19 pandemic: a rapid turnaround global survey. 2020. https://www.medrxiv.org/content/10.1101/2020.05.17.2 0101915v1.full.pdf+html. Accessed $12 \mathrm{Jul} 2020$.

43. Adams JG, Walls RM. Supporting the health care workforce during the COVID- 19 global epidemic. JAMA. 2020;323:1439-40.

44. Liu N, Zhang F, Wei C, Jia Y, Shang Z, Sun L, Wu L, Sun Z, Zhou Y, Wang Y, Liu W. Prevalence and predictors of PTSS during COVID-19 outbreak in China hardest-hit areas: Gender differences matter. Psychiatry Res. 2020;287: 112921

45. Wang C, Pan R, Wan X, Xu L, Ho CS, Ho R. Immediate psychologival responses and associated factors during the inicial stage of the 2019 coronavirus disease (COVID-19) epidemic among the general population in China. Int J Environ Res Public Health. 2020;17(5):1729.

46. Okwaraji FE, Aguwa EN. Burnout and psychological distress among nurses in a Nigerian tertiary health institution. Afr Health Sci. 2014;14(1):237-45.

47. Diário da República II série, 4396. Estabelece regras aplicáveis aos profissionais de saúde, com filho ou outros dependentes a cargo menores de 12 anos [Establishes rules for health professionals, with dependent children or other dependents under 12 years old]. 2020. https://dre.pt/ application/conteudo/131338906 Accessed 12 Jul 2020.

48. Lipp ME. Teoria de temas de Vida do stress recorrente e crónico [theory of life themes of recurrent and chronic stress]. Boletim Acad Paulista Psicologia. 2006;3(6):82-93 https://www.redalyc.org/articulo.oa?id=946/ 94626311.

49. Cole AH. Anxiety. In: Leeming DA, editor. Encyclopedia of psychology and religion. 2nd ed. New York: Springer; 2014

50. Spielberger CD. Theory and research on anxiety. In C.D. Spielberger editors Anxiety and behavior. New York: Academic Press; 1966. p. 3-19.

51. Chirico F, Magnavita N. The crucial role of occupational health surveillance for health-care workers during the COVID-19 pandemic. Workplace Health Saf. 2020; 20(10):1-2.

\section{Publisher's Note}

Springer Nature remains neutral with regard to jurisdictional claims in published maps and institutional affiliations.

Ready to submit your research? Choose BMC and benefit from:

- fast, convenient online submission

- thorough peer review by experienced researchers in your field

- rapid publication on acceptance

- support for research data, including large and complex data types

- gold Open Access which fosters wider collaboration and increased citations

- maximum visibility for your research: over $100 \mathrm{M}$ website views per year

At $\mathrm{BMC}$, research is always in progress.

Learn more biomedcentral.com/submissions 